\title{
PERSONNEL NEUTRON MONITORING AROUND HIGH ENERGY ACCELERATORS
}

\author{
M. Höfert, CERN, Geneva, Switzerland
}

D.T. Bartlett, NRPB, Didcot, United Kingdom

E. Piesch, KFK Karlsruhe, Federal Republic of Germany

\begin{abstract}
Personnel neutron monitoring around high-energy proton accelerators can derive benefit from the fact that energetic components usually present in the stray field allow the use of detectors with relatively high energy thresholds. In a series of experiments the behaviour of various track etch detectors towards radiation outside the main shield of the CERN proton accelerators was compared. Because of the extended energy range that has to be covered, none of the presently available detectors can be considered as a personnel dosimeter. In most practical cases, however, the dosimetry aspect is negligible since dose rates in accessible areas are kept low. Under such favourable conditions the radiation monitoring features of the investigated detectors become important.
\end{abstract}

To be presented at the

Workshop on Development of Personal Neutron Dosemeters

Based on Track Etch Detectors

Harwe11, May 12-14 1987 


\section{INTRODUCTION}

The radiation field penetrating the usually thick shielding of high energy accelerators is a mixed field with a multitude of components. Stray neutrons are of particular importance in radiation protection considering their quality factor greater than one. Area and personnel dosimetry become a challenging task in a spectrum extending from thermal energies up to the primary energy of the accelerator. For neutrons above $20 \mathrm{MeV}$, strong interactions with material grow in importance with respect to energy deposition and neutrons become indistinguishable from other hadrons in their dosimetric properties.

\section{PERSONNEL DOSIMETRY VERSUS MONITORING}

Long before the ALARA concept had been clearly formulated and the ICRP pronounced the commandment: thou shalt not expose people, neutron dose rates of a few mrem per hour in experimental areas at CERN were considered to be less acceptable than much higher radiation levels from induced radioactivity inside accelerator tunnels or target regions during a shut-down. Several reasons, besides that of accessibility to these areas, are responsible for this attitude: high levels of stray radiation over extended areas create problems such as neutron skyshine at the CERN boundaries. There is a feeling that neutrons, evaluated in terms of dose equivalent, may still present a higher radiation risk than photons. The lack of a suitable personnel neutron dosemeter was sorely felt, as the NTA film due to the fading of latent tracks practically never showed a dose, in spite of the fact that the energy range of the neutrons present in the stray field should allow their detection.

The message was clear and in line with the CERN radiation protection philosophy: conceive all installations in such a way that neutron dose rates in accessible areas stay low enough to render a personnel neutron dosemeter superfluous. This does not mean, however, that a personnel neutron monitor would not be useful, considering the freedom of movement of experimental physicists working around high energy particle beams. As a stable operation of beams can never be fully guaranteed, the extensive radiation monitoring system in experimental areas of CERN has to be backed up by personnel hadron monitoring. 


\section{EARLIER DETECTOR DEVELOPMENT AND TESTS}

Taking into account the fact that the spectrum of stray hadrons outside a thick shield extends to the highest energies with an approximate $1 / E$ dependence led to the idea that LR115, a detector made of $14 \mu \mathrm{m}$ of red-dyed cellulose nitrate on a transparent plastic layer and having an energy threshold of about $4 \mathrm{MeV}$, compared with $1 \mathrm{MeV}$ for the NTA emulsion, could possibly be employed as a personnel monitor. An extensive research programme carried out at CERN revealed, however, that LR115, after the problem of its reproducibility had been overcome, could not be used because of its high background of great variability [1-4]. Efforts then turned towards improving the fading properties of the NTA emulsion [5-8]. With funds for personnel dosemeter research practically nonexistant, activities had to be concentrated on testing detectors developed by other laboratories in CERN stray fields. At present the NTA emulsion sealed in dry nitrogen by NRPB is carried at CERN for periods of two months. Fading, negligible for thick dark tracks from source neutrons but still noticeable for thin long tracks recorded in a high energy hadron field, is offset by using the conservative dose equivalent conversion factor valid for Pu-Be neutrons. This conversion should represent an overestimation of the personnel dose in most cases.

Practical experience over two years with the nuclear emulsion has shown the validity of the present approach as the usually small exposures of less than $1 \mathrm{mSv}$ recorded for a two-month period correspond to values to be expected from area monitoring. Only in one case so far was an appreciable number of tracks detected, and by cautiously employing the method of track length analysis a personnel dose was attributed to the wearer which compared well with the one established after reconstruction of the event.

In view of the low radiation risk from hadrons at CERN and taking the $1 / E$ spectral dependence into account, it would be reasonable to opt for a hadron detector with an energy threshold and no fading which could be worn for three-month periods. The result of such a monitor could be evaluated in a conservative manner, attributing small doses to the wearer. Both the albedo detector and CR39 show a decreasing response with increasing energy, and do not fulfill the threshold condition. Thus a dose equivalent conversion factor based on their low sensitivity to high energy hadrons could lead to unacceptable and unrealistic overestimations of personnel doses. 
The basic characteristics of nuclear track detectors, when exposed to $\mathrm{Pu}-\mathrm{Be}$ neutrons, are presented in Table 1 for comparison. Of particular interest is the variation of the background, which will determine both the lower detection limit and the precision of the result. Following a proposal by Piesch [9] the relative standard deviation for the four detectors was calculated and is plotted in Fig. 1 as a function of dose equivalent. The uncertainty of a dose estimation varies considerably with the detector type. At high doses, however, all detectors show similar values. For a dose of $1 \mathrm{mSv}$ the relative standard deviation for LR 115 is $41 \%$ and can barely be improved by increasing the detector size.

In the case of the NTA film larger surfaces can always be scanned to decrease the uncertainty, but the manpowercost of scanning as well as the problem of fading should not be forgotten.

For Makrofol the situation is comparable to CR39 with respect to background and reproducibility. Its response to dose equivalent in the isotropic high-energy hadron stray field is, surprisingly, found to be smaller than the one for source neutrons of normal incidence. An assumed area of $3 \mathrm{~cm}^{2}$ may impose a limitation on detector size.

Finally CR39 turns out to be a sensitive detector, but with a relatively high background. Both sensitivity and background depend on the electrochemical etching technique applied [10-13]. Before any final judgment for the special applications at CERN is made, the results of test irradiations performed at CERN in 1985 and 1986 must be pondered.

\section{RESULTS OF TEST EXPOSURES}

Reference doses free in air were determined with the help of the multidetector set CERBERUS [14]. The hadron stray radiation field is characterized by fast and low-energy neutrons as measured with a $\mathrm{BF}_{3}$ ionization chamber placed inside an Andersson and Braun moderator. Particles above $20 \mathrm{MeV}$ are evaluated using activation technique, i.e. the transformation of ${ }^{12} \mathrm{C}$ into ${ }^{11} \mathrm{C}$ as a result of hadronic reactions in a big plastic scintillator. The multidetector method provides information on the hardness of the spectrum and percentages of high energy particles correspond well with results from a track length analysis performed in the NTA emulsion. 
The results for the various neutron detectors used in the test irradiations are presented in Tables 2 and 3. In order to facilitate their comparison all reported dose values were normalized to the reference dose. Uncertainties are standard deviations of the weighted mean of at least three detectors fixed on a cylindrical phantom with elliptic cross section in each position and exposed.

There is good agreement between track detector results and exposures performed at the $\mathrm{Pu}-\mathrm{Be}$ source (in the case of Makrofol detector irradiation with $\mathrm{Cf}$ neutrons), as dosemeters are normally calibrated in such a field or in a similar spectrum from Am-Be neutrons. These irraditions show a problem with respect to track length analysis in the NTA emulsion, since for the same spectrum important variations are observed. When using the information a mean track length for correcting the dose result with respect to the hardness of the spectrum, caution has to be taken as the mean track length is a strong function of the angle of incidence and isotropy in stray radiation fields. An improvement in the agreement between irradiation and reported dose is generally noticed in the case of very hard spectra, although in routine work such corrections are not applied, as has already been mentioned.

Due to their respective energy thresholds of 0.8 and $3 \mathrm{MeV}$, the NTA emulsion and Makrofol show low doses when exposed to $252 \mathrm{Cf}$ neutrons, but calibrated with a $\mathrm{Pu}-\mathrm{Be}$ source. Dramatic underestimation in fields outside labyrinths when low energy neutrons dominate the dose equivalent are expected for these detectors. In particular, Makrofol will not detect contributions to dose equivalent below its energy threshold in typical hadron stray fields.

In the case of CR39 the response in a soft spectrum is much better than that of the other threshold detectors. It must however be stressed that the "usual" stray radiation field at CERN is determined by hadrons outside a concrete or earth shield, i.e. the hard component above $10 \mathrm{MeV}$ predominates. Under these circumstances the expected underestimation of CR39 is clearly confirmed, with factors varying between two and five. It seems, however, that a track-to-dose equivalent conversion factor could be defined for this detector type which would give a reasonable answer on personnel doses without too much over- or underestimation. In particular, the two-step electrochemical etching technique increases the response for neutron energies above 5 MeV significantly [13]. 
In the case of a bare iron shielding, low energy neutrons penetrate predominantly in addition to the hard component. The response of CR39 in such a case is improved whereas the NTA film shows some underestimation. A curious and unexplained phenomenon of a great overestimation was observed in a radiation field created by the interaction of a $200 \mathrm{GeV}$ pion beam in a uranium collimator.

Calibration results with Makrofol are extremely good. The considerable underestimation in hard spectra could be explained by the presence of low-energy neutrons, also indicated by the albedo detector. The drawback of the higher threshold cannot be overcome by introducing thicker radiators in front of the detector.

Finally a thermoluminescence albedo detector was employed in the 1986 irradiation series. With the results presented as an equivalent ${ }^{137} \mathrm{Cs}$ exposure, clearly no correspondence between the reported figures and hadron doses was expected. It is therefore remarkable that values quoted in stray radiation fields are not more off than a factor of two from the hadron dose. The albedo response observed clearly depends on the spectrum hardness. Hence it is generally lower for high-energy neutrons, i.e. radiation fields characterized by long tracks recorded in the NTA emulsion. It seems that the so-called albedo flag announcing a neutron exposure could be used profitably in any future dosemeter system. In this respect the two-component albedo dosemeter, in combination with Makrofol - recommended in the Federal Republic of Germany for personnel monitoring around particle accelerators - would indicate, in the present intercomparison, consistent results better than within a factor of two, including calibration exposures with $\mathrm{Pu}-\mathrm{Be}$ neutrons.

\section{CONCLUSIONS}

A series of test irradiations with various nuclear track detectors performed in the stray field around the CERN proton accelerators has shown that a neutron dosemeter for extended energy ranges does not exist. However, in view of the fact that people are not allowed to work in irradiation fields of high neutron dose rates (it was indeed difficult to find suitable places for the test irradiation in order to accumulate doses of the order of $1 \mathrm{mSv}$ within a reasonable time) personnel neutron monitoring could be introduced on a quarterly basis. 
A three-month wearing period would mean a saving and yet allow exposure conditions to be established (even though it may be a long time after the fact) in case a high signal is recorded on a detector. At present the choice of detector leans towards CR39 provided a long-term supply of detectors of reproducible response and low reproducible background can be guaranteed. 


\section{REFERENCES}

1. M. Höfert, J. Dutrannois, E. Piesch and A. Janett, Investigation of the response of personnel dosimetry systems in hadron fields around the CERN $28 \mathrm{GeV}$ Proton Synchrotron, CERN HS-RP/004 (1976).

2. M. Höfert, An approach to a personnel neutron monitor based on a nuclear track detector, Proc. 7th DOE Workshop on Personnel Neutron Dosimetry, London, 1978, in PNL-2807/UC-48, page 79, Battelle Northwest, 1978.

3. M. Höfert and A. Koczynski, Hadron personnel monitoring around high-energy proton accelerators, Proc. 8th DOE Workshop on Personnel Neutron Dosimetry, Louisville 1981, in PNL-SA-9950, page 51, Battelle Nortwest, 1981.

4. M. Höfert, Two years of practical experience with LR115 as a hadron detector, Proc. 12th Int. Conf. on Solid State Nuclear Track Detectors, Acapulco 1983, in Nuclear Tracks 8,317 (1983).

5. D.T. Bartlett and F.L. Creasey, Latent image fading in nuclear emulsions, Phys. Med. Biol. 22, 736 (1977).

6. D.T. Bartlett, Personnel neutron monitoring at the NRPB, Proc. 7 th DOE Workshop on Personnel Neutron Dosimetry, London 1978, in PNL-2807/UC-48, page 46, Battelle Northwest, 1978.

7. M. Höfert, The NTA emulsion: An ill-reputed but misjudged neutron detector, Proc. 10th DOE Workshop on Personnel Neutron Dosimetry, Acapulco 1983, in CONF-8308/40-PNL-SA-12352, page 107, Battelle Northwest, 1984.

8. M. Höfert and F. Lehmann, Fading of tracks from high-energy hadrons in the NTA emulsion, Presented at the Personnel Radiation Dosimetry Symposium in Knoxville 1984, CERN TIS-RP/135/CF (1984).

9. E. Piesch, J. Jasiak and M. Urban, Makrofol and CR-39 detectors as a supplement of a universal albedo neutron dosemeter, Nuclear Tracks and Radiation Measurements $\underline{8}, 326$ (1984).

10. J.R. Harvey and A.R. Weeks, Progress towards the development of a personal neutron dosimetry system based on the chemical etch of CR39, General Electricity Generating Board Report TPRD/B/085/R86, 1986 . 
11. D.T. Bartlett, J.D. Steele and D.R. Stubberfield, Development of a single element neutron personal dosemeter for thermal, epithermal and fast neutrons, Nuclear Tracks 12, 645 (1986).

12. E. Piesch and M. Urban, Dosimetric properties of different CR39 plastics used as neutron recoil track etch detectors, Nuclear Tracks 12, 661 (1986).

13. S.A.R. Al-Najjar and E. Piesch, Further investigation of neutron energy response of CR-39 detectors, paper to be presented at the Harwell Workshop on Development of Personal Neutron Dosemeters Based on Track Etch Detectors, 1987.

14. M. Höfert and G.R. Stevenson, Dose equivalent measurements around GeV accelerators, Rad.Prot.Dos. 9, 235 (1984). 
Table 1: Basic characteristics of nuclear track detectors

\begin{tabular}{|c|c|c|c|c|c|}
\hline & NTA film [4] & LR115 [4] & Makrofol & $\operatorname{CR} 39[11]^{2}$ & CR39 $[12]^{3}$ \\
\hline $\begin{array}{l}\text { Dose equivalent response } \\
\text { for } \mathrm{Pu}-\mathrm{Be} / \mathrm{Am} \text { neutrons of } \\
\text { normal jncidęnce } \\
\text { in } \mathrm{mSv}^{-1} \mathrm{~cm}^{-2}\end{array}$ & $1.63 \times 10^{5}$ & 3.4 & 22 & 80 & 430 \\
\hline $\begin{array}{l}\text { Typical dose equivalent } \\
\text { response for hadron stray } \\
\text { fields of isotropic incidence } \\
\text { in } \mathrm{mSv}^{-1} \mathrm{~cm}^{-2}\end{array}$ & $3.5 \times 10^{5}$ & 14 & 6 & 34 & 175 \\
\hline Background holes or tracks per $\mathrm{cm}^{2}$ & $1.21 \pm 0.99 \times 10^{4}$ & $8.1 \pm 3.6$ & $3.6 \pm 0.9$ & $10 \pm 5$ & $60 \pm 16$ \\
\hline Standard field size in $\mathrm{cm}^{2}$ & $8.75 \times 10^{-3}$ & 1.44 & 3.14 & 1.68 & 1 \\
\hline BG per standard field size & $1.06 \pm 0.87$ & $11.6 \pm 5.2$ & $11.3 \pm 2.8$ & $17 \pm 8$ & $60 \pm 16$ \\
\hline $\begin{array}{l}\text { Number of tracks per mSv } \\
\text { (standard field size) in } \\
\text { typical stray hadron field }\end{array}$ & 31 & 20 & 18 & 57 & 175 \\
\hline $\begin{array}{l}\text { Relative standard deviation } \\
\text { of detector at } 10 \mathrm{mSv} \text {, } \\
\text { response in } \%\end{array}$ & 12.5 & 14 & 11.7 & 15 & 15 \\
\hline
\end{tabular}

1) Track detectors will mainly register radiation from the front half sphere when irradiated on a phantom.

2) Manufactured by Pershore Moulding, pre-etched before electrochemical etching (NRPB).

3) Manufactured by Pershore Moulding, two-step electrochemical etching technique (KFK). 
Table 2: Test irradiations 1985

\begin{tabular}{|c|c|c|c|c|c|c|c|}
\hline \multicolumn{5}{|c|}{ Irradiation conditions } & \multicolumn{3}{|c|}{ Results in $\mathrm{H} / \mathrm{Href}$} \\
\hline \multirow{2}{*}{$\begin{array}{l}\text { Location of } \\
\text { experiment }\end{array}$} & \multirow{2}{*}{$\begin{array}{l}\text { Hadron } \\
\text { dose } \\
\text { Href } \\
\text { in } m S v\end{array}$} & \multirow{2}{*}{$\begin{array}{l}\text { Radiation type } \\
\text { (contribution of } \\
\text { C particles } \\
\text { in } \% \text { ) }\end{array}$} & \multirow{2}{*}{$\begin{array}{l}\text { Track } \\
\text { length } \\
\text { in } \mu \mathrm{m}\end{array}$} & \multirow{2}{*}{$\begin{array}{l}\text { Mean } \\
\text { energy } \\
\text { in } \mathrm{MeV}\end{array}$} & \multicolumn{2}{|c|}{$\begin{array}{c}\text { NTA CERN } \\
\text { packed by NRPB }\end{array}$} & \multirow{2}{*}{$\begin{array}{l}\text { CR39 } \\
\text { NRPB }\end{array}$} \\
\hline & & & & & 1) & 2) & \\
\hline $\begin{array}{l}\text { AA outside door } \\
\text { bldg } 306\end{array}$ & & $\begin{array}{l}\text { Soft spectrum } \\
\text { (thermal neutrons) }\end{array}$ & & 2.7 & $0.12 \pm 0.01$ & $0.17 \pm 0.03$ & \\
\hline & 2.35 & $-"-(0 \%)$ & $18.3 \pm 5.8$ & 2.9 & $0.10 \pm 0.04$ & $0.10 \pm 0.06$ & $0.41 \pm 0.07$ \\
\hline \multirow[t]{2}{*}{$\begin{array}{l}\text { Calibration } \\
\text { barrack }\end{array}$} & 1.0 & $\begin{array}{l}\text { Pu-Be source } \\
\text { neutrons }\end{array}$ & $14.1 \pm 1.0$ & 2.8 & $1.06 \pm 0.29$ & $1.46 \pm 0.44$ & $1.03 \pm 0.25$ \\
\hline & 3.0 & $-"-$ & $14.8 \pm 1.8$ & 3.6 & $1.12 \pm 0.10$ & $1.07 \pm 0.09$ & $0.97 \pm 0.15$ \\
\hline $\begin{array}{l}\text { West Hall } \\
\text { Omega }\end{array}$ & 1.45 & $\begin{array}{l}\text { Uranium block } \\
\text { serving as target } \\
(10 \%)\end{array}$ & $22.7 \pm 4.2$ & 4.4 & $2.5 \pm 0.12$ & $1.82 \pm 0.09$ & $4.62 \pm 0.38$ \\
\hline $\begin{array}{l}\text { AA inside } \\
\text { bldg } 195 \mathrm{R}-003\end{array}$ & 1.9 & $\begin{array}{l}\text { Iron shielding } \\
\text { predominant }(5 \%)\end{array}$ & $27.1 \pm 2.1$ & 5.9 & $0.81 \pm 0.08$ & $0.39 \pm 0.04$ & $0.69 \pm 0.09$ \\
\hline PS East Hall & 0.65 & $\begin{array}{l}\text { Typical spectrum } \\
\text { near concrete } \\
\text { shielding }\end{array}$ & $33.1 \pm 4.1$ & 8.0 & $2.55 \pm 0.31$ & $1.09 \pm 0.17$ & $0.68 \pm 0.12$ \\
\hline SPS North Hall (2) & 0.7 & $-"-(15 \%)$ & $39.2 \pm 2.6$ & 10.1 & $3.18 \pm 0.53$ & $1.19 \pm 0.20$ & $0.54 \pm 0.13$ \\
\hline SPS North Hall (1) & 0.8 & $-"-(17 \%)$ & $40.1 \pm 10$ & 10.4 & $2.85 \pm 0.13$ & $1.04 \pm 0.05$ & $0.53 \pm 0.06$ \\
\hline
\end{tabular}

1) Standard interpretation

2) Interpretation using information on track lengths 
Table 3: Test irradiation 1986

\begin{tabular}{|c|c|c|c|c|c|c|c|c|c|c|c|}
\hline \multicolumn{6}{|c|}{ Irradiation conditions } & \multicolumn{6}{|c|}{ Results in $\mathrm{H} / \mathrm{Href}$} \\
\hline \multirow{2}{*}{$\begin{array}{l}\text { Location of } \\
\text { experiment }\end{array}$} & \multirow{2}{*}{\multicolumn{2}{|c|}{$\begin{array}{l}\text { Hadron dose } \\
\text { Href } \\
\text { in mSv } \\
\text { (photons) }\end{array}$}} & \multirow{2}{*}{$\begin{array}{l}\text { Radiation type } \\
\text { ( fontribution of } \\
\text { C particles } \\
\text { in } \%)\end{array}$} & \multirow{2}{*}{$\begin{array}{l}\text { Track } \\
\text { length } \\
\text { in } \mu \mathrm{m}\end{array}$} & \multirow{2}{*}{$\begin{array}{l}\text { Mean } \\
\text { energy } \\
\text { in MeV }\end{array}$} & \multicolumn{2}{|c|}{$\begin{array}{c}\text { NTA CERN }{ }^{3} \\
\text { packed by NRPB }\end{array}$} & \multirow{2}{*}{$\begin{array}{l}\text { CR39 } \\
\text { NRPB }^{3}\end{array}$} & \multirow{2}{*}{$\begin{array}{l}\text { CR39 } \\
\mathrm{KFK}^{3}\end{array}$} & \multirow{2}{*}{$\begin{array}{l}\text { Makrofol } \\
3 \text { detect. } \\
\text { KFK }^{4}\end{array}$} & \multirow{2}{*}{$\begin{array}{l}\text { Albedo } \\
\text { dosemeter } \\
\mathrm{KFK}^{5}\end{array}$} \\
\hline & & & & & & 1) & 2) & & & & \\
\hline $\begin{array}{l}\text { Calibration } \\
\text { barrack }\end{array}$ & & $\begin{array}{l}1.0 \\
(0)\end{array}$ & $\begin{array}{l}252 \mathrm{Cf} \\
\text { Source neutrons }\end{array}$ & $14.8 \pm 0.2$ & 3.6 & $0.67 \pm 0.04$ & $0.75 \pm 0.04$ & $1.21 \pm 0.02$ & $0.94 \pm 0.08$ & $1.17 \pm 0.08$ & $0.18 \pm 0.02$ \\
\hline $\begin{array}{l}\text { Calibration } \\
\text { barrack }\end{array}$ & & $\begin{array}{l}1.0 \\
(0)\end{array}$ & $\begin{array}{l}\mathrm{Pu}-\mathrm{Be} \\
\text { Source neutrons }\end{array}$ & $17.6 \pm 1.5$ & 7.0 & $1.04 \pm 0.09$ & $0.65 \pm 0.06$ & $0.80 \pm 0.05$ & $1.04 \pm 0.3$ & $1.97 \pm 0.2$ & $0.19 \pm 0.02$ \\
\hline $\begin{array}{l}\text { Calibration } \\
\text { barrack }\end{array}$ & & $\begin{array}{l}3.0 \\
(0)\end{array}$ & $\begin{array}{c}\mathrm{Pu}-\mathrm{Be} \\
\text { Source neutrons }\end{array}$ & $15.6 \pm 2.6$ & 4.6 & $1.11 \pm 0.06$ & $0.93 \pm 0.05$ & $0.83 \pm 0.02$ & $0.95 \pm 0.03$ & $1.92 \pm 0.06$ & $0.16 \pm 0.02$ \\
\hline SPS North Hall & (3) & $\begin{array}{l}2.6 \\
(0.7)\end{array}$ & $\begin{array}{l}\text { Near an access } \\
\text { door }(16 \%)\end{array}$ & $22.1 \pm 2.2$ & 4.2 & $1.32 \pm 0.12$ & $1.28 \pm 0.12$ & $0.89 \pm 0.10$ & $0.5 \pm 0.07$ & $0.52 \pm 0.04$ & $2.09 \pm 0.17$ \\
\hline $\mathrm{SC}$ & & $\begin{array}{l}1.9 \\
(0.15)\end{array}$ & $\begin{array}{l}\text { Behind thick } \\
\text { shielding wall } \\
\text { (rem counter, } 0 \% \text { ) }\end{array}$ & $22.9 \pm 4.5$ & 4.5 & $0.81 \pm 0.08$ & $0.72 \pm 0.07$ & $1.29 \pm 0.19$ & $1.04 \pm 0.26$ & $0.29 \pm 0.06$ & $1.86 \pm 0.16$ \\
\hline SPS North Hall & $(1)$ & $\begin{array}{l}1.0 \\
(0.5)\end{array}$ & $\begin{array}{l}\text { Near uranium } \\
\text { collimator }(5 \%)\end{array}$ & $31.2 \pm 8.6$ & 7.3 & $0.53 \pm 0.03$ & $0.33 \pm 0.02$ & $0.095 \pm 0.06$ & $<0.2$ & $0.25 \pm 0.06$ & $0.75 \pm 0.12$ \\
\hline SPS West Hall ( & (1) & $\begin{array}{l}1.4 \\
(0.5)\end{array}$ & $\begin{array}{l}\text { Typical spectrum } \\
\text { near concrete } \\
\text { shielding }(10 \%)\end{array}$ & $34.1 \pm 4.6$ & 8.3 & $1.41 \pm 0.10$ & $0.80 \pm 0.06$ & $0.38 \pm 0.04$ & $0.34 \pm 0.02$ & $0.38 \pm 0.06$ & $0.54 \pm 0.07$ \\
\hline SPS West Hall ( & (2) & $\begin{array}{l}1.0 \\
(0.5)\end{array}$ & $-"-(10 \%)$ & $36.0 \pm 8.5$ & 9.0 & $2.42 \pm 0.43$ & $1.35 \pm 0.24$ & $0.64 \pm 0.10$ & $0.59 \pm 0.12$ & $0.71 \pm 0.16$ & $1.32 \pm 0.2$ \\
\hline SPS North Hall & $(2)$ & $\begin{array}{l}2.2 \\
(0.45)\end{array}$ & $-"-(8 \%)$ & $54.0 \pm 20$ & 15.2 & $1.30 \pm 0.02$ & $0.56 \pm 0.01$ & $0.17 \pm 0.03$ & $0.29 \pm 0.08$ & $0.48 \pm 0.04$ & $1.11 \pm 0.25$ \\
\hline
\end{tabular}

1) Standard interpretation

4) Calibration with ${ }^{252} \mathrm{Cf}$ source

2) Interpretation using information on track lengths

3) Calibration with $\mathrm{Am}-\mathrm{Be} / \mathrm{Pu}-\mathrm{Be}$ sources

5) Calibration with ${ }^{137} \mathrm{Cs}$ source 


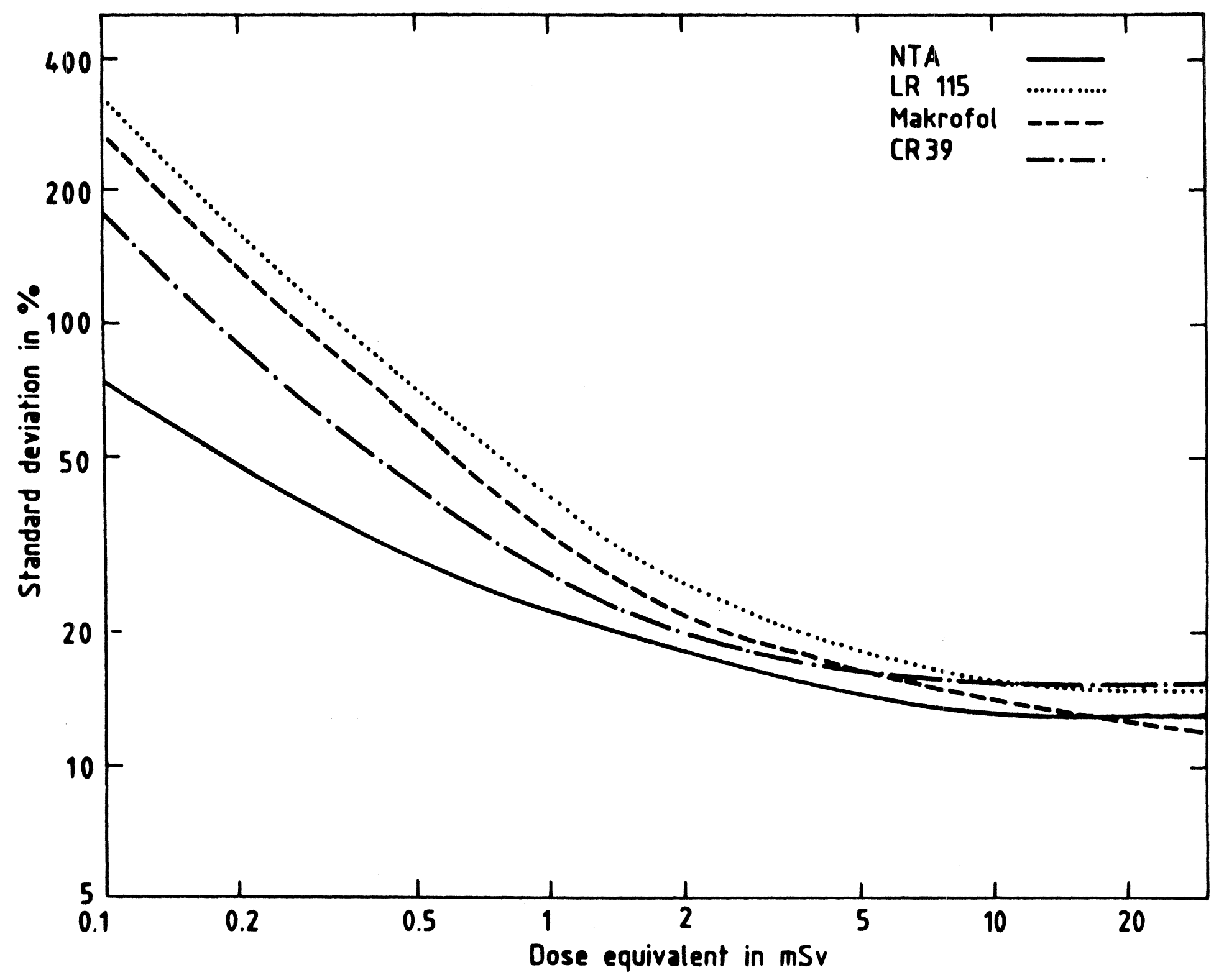

Relative uncertainty in percent of reported doses expressed as overall standard deviation [9]. The curve for CR-39 was calculated for the NRPB detector. 